\title{
Article
}

\section{Id2 Represses Aldosterone-Stimulated Cardiac T-Type Calcium Channels Expression}

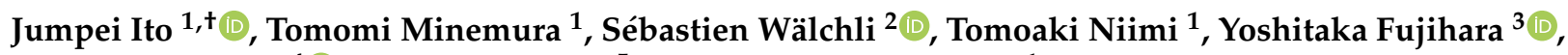 \\ Shun'ichi Kuroda ${ }^{4} \mathbb{D}$, Koichi Takimoto ${ }^{5}$ and Andrés D. Maturana ${ }^{1, *}$ \\ 1 Laboratory of Animal Cell Physiology, Graduate School of Bioagricultural Sciences, Nagoya University, \\ Aichi 464-8601, Japan; pha066@osaka-med.ac.jp (J.I.); mine@fbs.osaka-u.ac.jp (T.M.); \\ tniimi@agr.nagoya-u.ac.jp (T.N.) \\ 2 Translational Research Unit, Section for Cellular Therapy, Oslo University Hospital, 0379 Oslo, Norway; \\ sebastw@rr-research.no \\ 3 Department of Experimental Genome Research, Research Institute for Microbial Diseases, \\ Osaka 565-0871, Japan; fujihara@biken.osaka-u.ac.jp \\ 4 Institute for Scientific and Industrial Researches, Osaka University, Osaka 567-0047, Japan; \\ skuroda@sanken.osaka-u.ac.jp \\ 5 Department of Bioengineering, Nagaoka University of Technology, Nagaoka 940-2188, Japan; \\ koichi@vos.nagaokaut.ac.jp \\ * Correspondence: maturana@agr.nagoya-u.ac.jp; Tel.: +81-052-789-5015; Fax: +81-052-789-5237 \\ + Present address: Department of Pharmacology, Faculty of Medicine, Osaka Medical College, \\ Osaka 569-8686, Japan.
}

Citation: Ito, J.; Minemura, T.; Wälchli, S.; Niimi, T.; Fujihara, Y.; Kuroda, S.; Takimoto, K.; Maturana, A.D. Id2 Represses Aldosterone-Stimulated Cardiac T-Type Calcium Channels Expression. Int. J. Mol. Sci. 2021, 22, 3561. https://doi.org/10.3390/ijms22073561

Academic Editor: Luigi Petramala

Received: 9 March 2021

Accepted: 23 March 2021

Published: 30 March 2021

Publisher's Note: MDPI stays neutral with regard to jurisdictional claims in published maps and institutional affiliations.

Copyright: (c) 2021 by the authors. Licensee MDPI, Basel, Switzerland. This article is an open access article distributed under the terms and conditions of the Creative Commons Attribution (CC BY) license (https:// creativecommons.org/licenses/by/ $4.0 /)$

\begin{abstract}
Aldosterone excess is a cardiovascular risk factor. Aldosterone can directly stimulate an electrical remodeling of cardiomyocytes leading to cardiac arrhythmia and hypertrophy. Ltype and T-type voltage-gated calcium $\left(\mathrm{Ca}^{2+}\right)$ channels expression are increased by aldosterone in cardiomyocytes. To further understand the regulation of these channels expression, we studied the role of a transcriptional repressor, the inhibitor of differentiation/DNA binding protein 2 (Id2). We found that aldosterone inhibited the expression of Id2 in neonatal rat cardiomyocytes and in the heart of adult mice. When Id2 was overexpressed in cardiomyocytes, we observed a reduction in the spontaneous action potentials rate and an arrest in aldosterone-stimulated rate increase. Accordingly, Id2 siRNA knockdown increased this rate. We also observed that CaV1.2 (L-type $\mathrm{Ca}^{2+}$ channel) or CaV3.1, and CaV3.2 (T-type $\mathrm{Ca}^{2+}$ channels) mRNA expression levels and $\mathrm{Ca}^{2+}$ currents were affected by Id 2 presence. These observations were further corroborated in a heart specific Id2- transgenic mice. Taken together, our results suggest that Id2 functions as a transcriptional repressor for L- and T-type $\mathrm{Ca}^{2+}$ channels, particularly CaV3.1, in cardiomyocytes and its expression is controlled by aldosterone. We propose that Id 2 might contributes to a protective mechanism in cardiomyocytes preventing the presence of channels associated with a pathological state.
\end{abstract}

Keywords: aldosterone; cardiomyocytes; T-type calcium channels (List three to ten pertinent keywords specific to the article yet reasonably common within the subject discipline.)

\section{Introduction}

Aldosterone is associated with the development of heart pathologies, in particular hypertrophy, arrhythmia, and heart failure. Patients with aldosterone excess pathologies such as primary aldosteronism or Cushing's syndrome are also subject to heart diseases [1-5]. In vivo and in vitro studies have shown that aldosterone directly stimulates an electrical remodeling, altering the expression of cardiac ion channels promoting the development of cardiac hypertrophy and heart failure [6-9]. Particularly, the expression and activity of both cardiac L-type voltage-gated calcium $\left(\mathrm{Ca}^{2+}\right)$ channel (CaV1.2) and T-type voltagegated $\mathrm{Ca}^{2+}$ channels (CaV3.1 and CaV3.2) are up-regulated by aldosterone in isolated neonatal and adult rat ventricular cardiomyocytes [10-12]. In the heart ventricle, the 
calcium influx through the L-type $\mathrm{Ca}^{2+}$ channels sustains the depolarization phase of the cardiac action potential and the excitation-contraction coupling [6]. T-type voltage-gated $\mathrm{Ca}^{2+}$ channels drive the pacemaker depolarization of the sinoatrial node of the heart [13]. The re-expression of T-type $\mathrm{Ca}^{2+}$ channels in the adult ventricle is associated with the development heart hypertrophy and failure [14].

The regulation of the CaV3.1 T-type $\mathrm{Ca}^{2+}$ channels expression by corticosteroid involves in five Glucocorticoid Response Elements (GRE) in the promoter of cacna1g gene, encoding for the CaV3.1 T-type $\mathrm{Ca}^{2+}$ channels $[12,15]$. Interestingly, these GRE elements act either as repressor or activator on CaV3.1 expression [15]. The expression of CaV3.1 and CaV3.2 are also regulated by miRNA204 whose expression is upregulated by aldosterone stimulation [16]. miRNA204 downregulates the expression of a transcriptional repressor REST/NRSF that blocks the expression of CaV3.2 T-type $\mathrm{Ca}^{2+}$ channels [16].

Inhibitor of differentiation/DNA binding protein 2 (Id2) is another transcriptional repressor that belongs to the family of Helix-Loop-Helix (HLH) transcription regulators [17]. Id2 lacks DNA binding domain, and acts as a dominant-negative factor upon dimerization with bHLH transcription factors [17]. Id2 is important for heart development during embryogenesis $[18,19]$. Id2 cooperates with Nkx2.5 and GATA4 transcription factors for the development of the cardiac conduction system [20]. In the murine embryonic carcinoma cell line P19, Id2 interacts with and blocks the activity of Nkx2.5 and GATA4, preventing these cells to differentiate into beating cardiomyocytes [21,22].

Since, at the molecular level, aldosterone alters the expression of genes involved in cardiomyocytes remodeling [23], we here studied Id2, an important regulator of heart development conduction system during embryogenesis $[18,20,24]$, as a candidate transcriptional regulator which could affect the expression of genes encoding the L-type and T-type voltage-gated $\mathrm{Ca}^{2+}$ channels. We here demonstrate that there is a link between aldosterone stimulation and Id 2 regulation. By using different molecular tools, we show that Id 2 can function as transcriptional repressor of voltage-gated $\mathrm{Ca}^{2+}$ channels and could possibly contribute to a protective mechanism in cardiomyocytes exposed to excess of aldosterone.

\section{Results}

\subsection{Aldosterone Represses Id2 Expression in Neonatal Rat Cardiomyocytes}

We first examined the expression of Id2 in the heart (Figure S1) and observed that Id2 mRNA and protein were found in the atria, septum, and left and right ventricle (Figure $\mathrm{S} 1 \mathrm{~A}, \mathrm{~B})$. The mRNA expression of Id2 increased after birth in the whole heart (Figure S1C). We next examined whether aldosterone stimulation could affect the expression of Id2 in neonatal rat ventricular cardiomyocytes. The mRNA level of Id2 was reduced after $24 \mathrm{~h}$ upon aldosterone stimulation (Figure 1A). The reduction reach significance from $100 \mathrm{nmol} / \mathrm{L}$ or higher doses of aldosterone (Figure 1A). Spironolactone, a mineralocorticoid receptor (MR) antagonist, prevented the effect of aldosterone to Id 2 mRNA expression in cardiomyocytes (Figure 1B). Accordingly, aldosterone stimulation $(1 \mu \mathrm{mol} / \mathrm{L})$ significantly reduced the protein amount of Id2 compared to control (Figure 1C). These results suggest that aldosterone trough the activation of MR represses the expression of Id2 in neonatal ventricular rat cardiomyocytes.

\subsection{Overexpression of Id2 Prevents the Aldosterone-Stimulated Effects on Cardiomyocytes}

Aldosterone stimulates an increased spontaneous beating rate on neonatal cardiomyocytes and positively or negatively alters the expression of cardiac ion channels [11,25-27]. As Id2 expression is repressed by aldosterone (Figure 1), we next assessed the effects of Id2 overexpression (Figure 1A) or siRNA knock-down (Figure 2B) on the rate of spontaneous action potential in neonatal rat cardiomyocytes (Figure 2C and Figure S2). Stimulation with aldosterone $(1 \mu \mathrm{mol} / \mathrm{L})$ for $24 \mathrm{~h}$ resulted in a significantly increased rate of spontaneous action potential compared to control. Id2 overexpression reduced the basal rate of spontaneous beating frequency. When Id2-overexpressing cardiomyocytes were stimulated with aldosterone, the rate of spontaneous action potential was similar to control. On the contrary, 
in cardiomyocytes treated with Id2 siRNA the rate was significantly higher than control cardiomyocytes. A Luc1 targeting siRNA used as control had no effect on the rate. These results suggested us a possible role of Id 2 in the regulation of cardiac ion channels expression. We, therefore, examined the mRNA expression of cardiac ion channels involved in the generation of the spontaneous action potentials (Figure 3 and Figure S3). As previously shown [11,12,26], $24 \mathrm{~h}$ aldosterone stimulation resulted in a significant increased expression of CaV1.2, CaV3.1, and CaV3.2 mRNA, encoding for the L- and T-type voltage-gated $\mathrm{Ca}^{2+}$ channels. Interestingly, the aldosterone stimulated an increase in CaV1.2, CaV3.1, CaV3.2 was suppressed in Id2 overexpressing cardiomyocytes (Figure 3A).

A

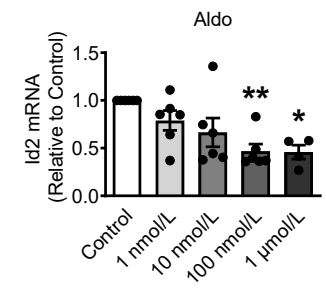

C

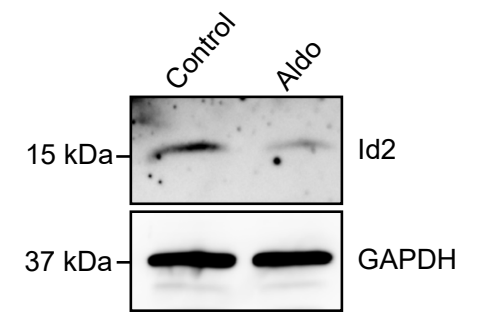

B

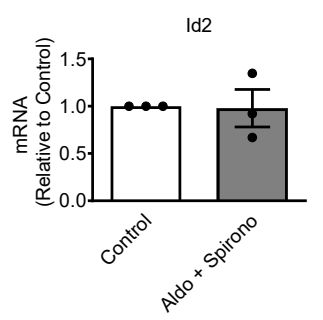

$\mathrm{D}$

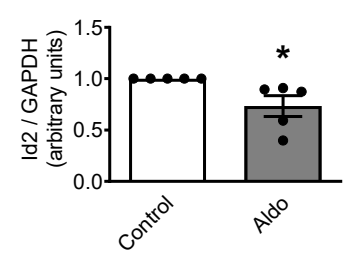

Figure 1. Aldosterone reduce the Id2 expression in neonatal rat ventricular cardiomyocytes. Neonatal rat cardiomyocytes were stimulated with (A) Aldo (aldosterone) or (B) $1 \mu \mathrm{mol} / \mathrm{L}$ Aldo + Spirono (Spironolactone) for $24 \mathrm{~h}$. Bar graphs show the Id2's mRNA level in aldosterone (Aldo)-treated and nontreated cardiomyocytes. Id 2 mRNAs were measured by real-time qPCR analysis ( $n=6$ for (A) and $n=3$ for $(\mathbf{B}))$. (C) Representative pictures of western blot experiments showing the Id2 protein (upper) and Glyceraldehyde 3-phosphate dehydrogenase (GAPDH) protein (lower) expression levels in neonatal rat ventricular cardiomyocytes treated with $1 \mu \mathrm{mol} / \mathrm{L}$ aldosterone (Aldo) for $24 \mathrm{~h}$. (D) The bar graph indicates the mean +/- s.e.m. of Id2 protein expression in aldosterone (Aldo)-treated $(1 \mu \mathrm{mol} / \mathrm{L})$ and non-treated cardiomyocytes from five independent experiments. The data were evaluated by one-way analysis of variance (ANOVA) followed by Tukey-Kramer's post hoc test or by unpaired two-tailed Student's $t$-test. Bar graphs are mean and + s.e.m, ${ }^{*} p<0.05,{ }^{* *} p<0.01$.

However, the expression of the Hcn 2 and Hcn 4 mRNAs, encoding the Hyperpolarizationactivated cyclic nucleotide-gated channels 2 and 4, and Kcnh2 and Kcnd3 mRNA, encoding the hERG and Kv4.3 potassium channels, were not changed by aldosterone stimulation (Figure S3). The voltage-gated sodium channel encoding scn $4 a$ mRNA, expression was slightly increased without reaching significance (Figure S3). Id2 overexpression increased the expression of Hcn 2 and Kcnh2. On the other hand, Scn5a and Kcnd3 expression were reduced upon Id2 overexpression. The siRNA knockdown of Id2 resulted in an increase in CaV1.2, CaV3.1, Hcn4, Scn5a mRNAs (Figure 3B and Figure S3). However, only the increase in CaV3.1 mRNA by Id2 siRNA reached statistical significance. Hcn 2 mRNA was on the contrary reduced.

These results thus suggest that Id 2 plays a role in the expression of cardiac ion channels, particularly the CaV3.1 T-type $\mathrm{Ca}^{2+}$ channels in neonatal rate ventricular cardiomyocytes. In addition, the suppression of aldosterone-stimulated increased expression of CaV1.2, 
CaV3.1, CaV3.2 suggests that Id2 could have a cardioprotective potential upon excess of aldosterone condition.

A

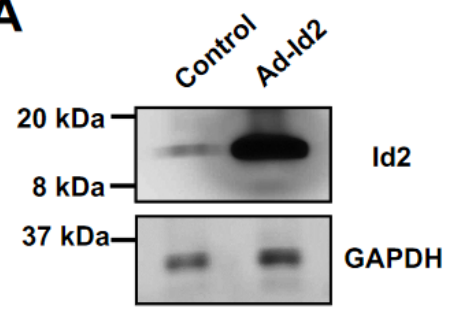

B
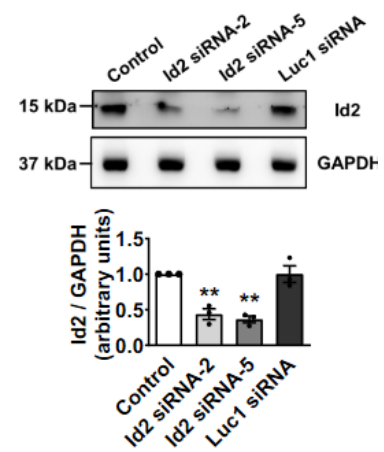

C

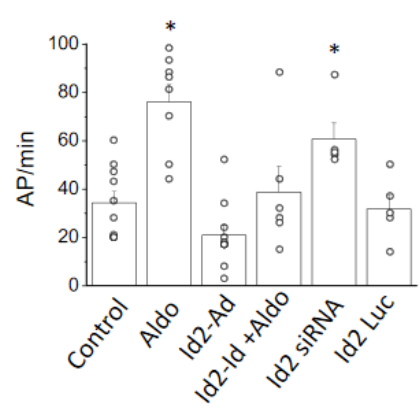

Figure 2. Effects of Id2 overexpression and siRNA knockdown on cardiomyocytes spontaneous action potential rate. (A) Id2 overexpression was achieved after $24 \mathrm{~h}$ transduction with adenoviral vector. Pictures of western blot experiments showing the Id2 protein (upper) and GAPDH protein (lower) expression levels in neonatal rat ventricular cardiomyocytes. (B) Id2 expression was knock down with siRNA. siRNAs were transfected for $48 \mathrm{~h}$ and proteins were extracted. Representative pictures of western blot experiments showing the Id2 protein (upper) and GAPDH protein (lower) expression levels in neonatal rat ventricular cardiomyocytes in control, Id2 targeting siRNA, and Luciferase (Luc) targeting siRNA. Bar graph are the mean of $n=3$ independent experiments. (C) Bar graph shows the number of spontaneous action potential per $\mathrm{min}$ in control, aldosterone treated $(1 \mu \mathrm{mol} / \mathrm{L})$, Id 2 overexpressing, Id 2 overexpressing with aldosterone $(1 \mu \mathrm{mol} / \mathrm{L}), \mathrm{Id} 2$ siRNA, and Luc1 siRNA cardiomyocytes. The data were evaluated by one-way analysis of variance (ANOVA) followed by Tukey-Kramer's post hoc test. Bar graphs are mean and + s.e.m, ${ }^{*} p<0.05,{ }^{* *} p<0.01$

\subsection{Id2 Expression Modulate the Voltage-Gated Calcium Currents in Cardiomyocytes}

We next tested the effect of Id2 overexpression and siRNA knockdown on the voltagegated $\mathrm{Ca}^{2+}$ channels activity of neonatal rat cardiomyocytes (Figure 4). Aldosterone stimulation with a concentration of $1 \mu \mathrm{mol} / \mathrm{L}$ significantly increased the voltage-gated $\mathrm{Ca}^{2+}$ currents from -30 to $+20 \mathrm{mV}$, a range voltage in which both T- and L-type $\mathrm{Ca}^{2+}$ channels are activated. Id 2 overexpression reduced the basal, as well as the aldosterone-stimulated increase in the voltage $\mathrm{Ca}^{2+}$ currents (Figure 4A). Inversely, Id2 siRNA knockdown significantly increased $\mathrm{Ca}^{2+}$ currents from -30 to $-10 \mathrm{mV}$, a range of voltages in which T-types $\mathrm{Ca}^{2+}$ channels are activated (Figure 4B). These results reinforce the hypothesis that Id2 acts as a transcriptional repressor for voltage-gated $\mathrm{Ca}^{2+}$ channels expression.

\subsection{Id2 Represses CaV3.1 Expression at the Transcriptional Level}

Among all the tested ion channels expression, CaV3.1 T-type $\mathrm{Ca}^{2+}$ channel, was the only whose expression was both significantly reduced by Id 2 overexpression, significantly increase upon Id2 siRNA knockdown and whose increased expression by aldosterone stimulation was prevented by Id2. These suggested us that Id 2 transcriptional repression may be specifically target $\mathrm{CaV} 3.1$. To further confirm that Id2 acts on the regulation of the CaV3.1 gene transcriptional activation, we tested whether Id2 prevents the aldosteroneinduced transcriptional activity on cacna1g gene, encoding for CaV3.1 T-type $\mathrm{Ca}^{2+}$ channel, 
using a luciferase reporter assay under the control of cacna1g $0.798 \mathrm{~kb}$ promoter (Figure 5). In neonatal rat cardiomyocytes, aldosterone $(1 \mu \mathrm{mol} / \mathrm{L})$ significantly induced transcriptional activation of cacna1g promoter compare to control. Id 2 overexpression significantly reduced the basal and the aldosterone-stimulated transcriptional activation. Id2 siRNA knockdown significantly stimulated the increase in cacna1g promoter activity. These results suggest that Id2 functions as a transcriptional repressor of CaV3.1 T-type $\mathrm{Ca}^{2+}$ channel.

A
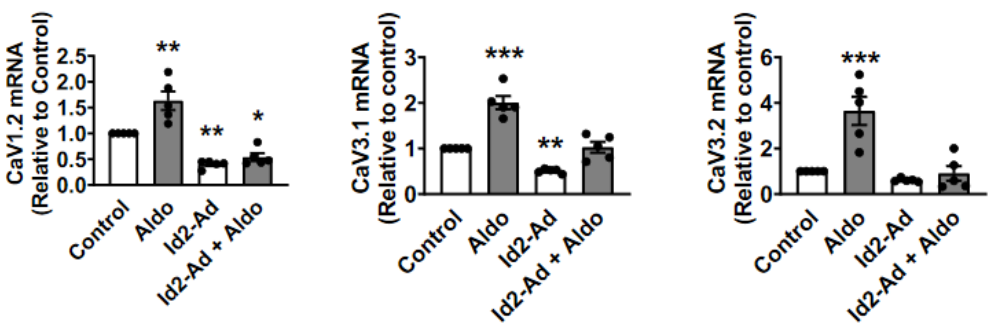

B
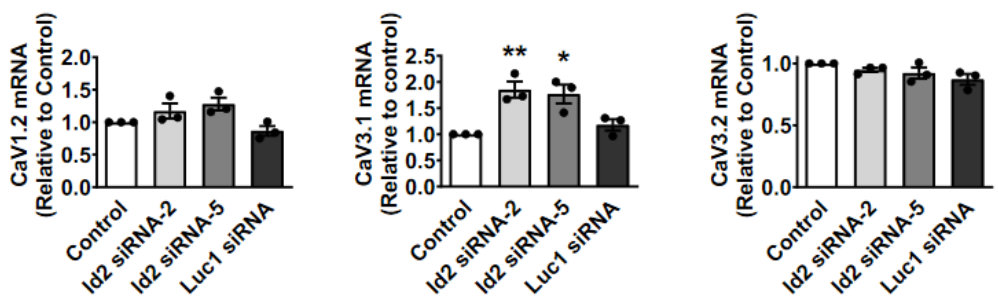

Figure 3. Manipulation of Id2's expression altered of voltage-gated calcium channel expression in neonatal rat ventricular cardiomyocytes and prevented aldosterone-stimulated increased. (A) 2, CaV3.1, and CaV3.2 were measured by RT-qPCR in neonatal rat ventricular cardiomyocytes treated and non-treated with $1 \mu \mathrm{mol} / \mathrm{L}$ Aldo for $24 \mathrm{~h}$ upon Id2 overexpression. Bar graphs shows the mean expression of CaV1.2 mRNA (left), CaV3.1 mRNA (middle), and CaV3.2 (right) $(n=5)$. (B) The mRNA expression of CaV1.2, CaV3.1, and CaV3.2 were measured by real-time qPCR in neonatal rat ventricular cardiomyocytes treated with Id 2 siRNA-2, siRNA-5 or Luciferase1 siRNA for 48 h. Bar graphs shows the mean expression of CaV1.2 mRNA (left), CaV3.1 mRNA (middle), and CaV3.2 (right) $(n=3)$. The data were evaluated by one-way analysis of variance (ANOVA) followed by Tukey-Kramer's post hoc test. Data are the mean \pm s.e.m, ${ }^{*} p<0.05,{ }^{* *} p<0.01 .{ }^{* * *} p<0.001$.

\subsection{Id2 Prevents the Aldosterone-Stimulated Increase in Voltage-Gated Calcium Channels in Adult Mouse Heart}

To confirm the repressive effect of Id 2 on $\mathrm{Ca}^{2+}$ channel expression in vivo, we generated a cardiomyocyte-specific Id 2 overexpressing mice (Figure 6 and Figure S4). These mice were viable and did not show any apparent phenotype difference with non-transgenic mice littermate (WT) at basal line (Table 1). To evaluate Id 2 role in adult heart, osmotic pumps containing aldosterone $(60 \mathrm{mg} / \mathrm{kg} /$ day) or a saline solution were implanted subcutaneously for 7 days in WT and Id2 transgenic mice. The heart of WT mice treated with aldosterone tended to be heavier but this difference did not reach significance compared to other groups in this period (Table 2, Table 3). In contrast to WT mice, Id2-transgenic mice showed no difference between aldosterone and saline treated mice for CaV1.2, CaV3.1, and CaV3.2 expression. These results corroborated in vivo that Id2 also represses the aldosterone-stimulated increase in L-type and T-type voltage-gated $\mathrm{Ca}^{2+}$ channels similarly to ventricle cardiomyocytes of neonatal rat. 
type

$\mathrm{Ca}^{2+}$

A

- Control

-๑-Aldo $(\mathrm{n}=$

$-\Delta-$ Id2-Ad I

$-\nabla-\operatorname{ld} 2-A d$

B

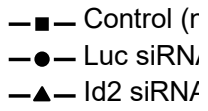

channel.
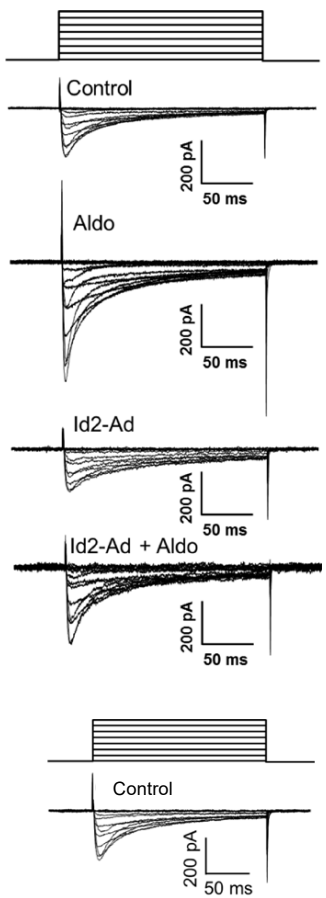

Luc1 siRNA

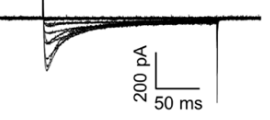

Id2 siRNA-5

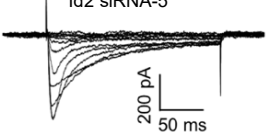

Figure 4. Manipulation of Id2's expression altered of voltage-gated $\mathrm{Ca}^{2+}$ currents in neonatal rat ventricular cardiomyocytes. Voltage-gated $\mathrm{Ca}^{2+}$ currents were measured by whole-cell patch-clamp experiments under the voltage-clamp mode. Graphs show the mean current-voltage relationship. currents measured in ventricular neonatal rat cardiomyocytes. (A) Graphs show the mean current-voltage relationship (IV curve) of voltage-gated $\mathrm{Ca}^{2+}$ currents measured in ventricular neonatal rat cardiomyocytes. $\mathrm{Ca}^{2+}$ currents were measured from a holding potential of $-90 \mathrm{mV}$ and depolarized by $10 \mathrm{mV}$ voltage steps to $+80 \mathrm{mV}$, as described in Methods. (A) IV curves recorded from cells that were treated (Aldo, $\bullet \square$ ) or non-treated (Control, $\mathbf{\square})$ with $1 \mu \mathrm{mol} / \mathrm{L}$ aldosterone for $24 \mathrm{~h}$ and in the same cells overexpressing Id2, treated (Id2-Ad + Aldo, $\mathbf{\Delta})$ or non-treated (Id2-Ad, $\mathbf{\nabla})$ with aldosterone (Aldo) at $1 \mu \mathrm{mol} / \mathrm{L}$. Right traces are representative recordings traces for cells non-treated (Control), treated (Aldo) with aldosterone at $1 \mu \mathrm{mol} / \mathrm{L}$ (Aldo) ( $\mathrm{n}=10$ to 11 cells). (B) IV curves of $\mathrm{Ca}^{2+}$ currents recorded in non-treated cardiomyocytes $(\mathbf{\square})$ and cardiomyocytes transfected with Id2 siRNA (siRNA Id2-5, $\mathbf{\Delta}$ ) or control siRNA (siRNA Luc1, $\bullet \square)(n=7-12$ cells). Data are the mean \pm s.e.m of 7 to 12 individual cardiomyocytes, as indicated in the figure for each condition from 3 to 4 different cell isolations. ${ }^{*} p<0.05$, from unpaired student's $t$-test. 

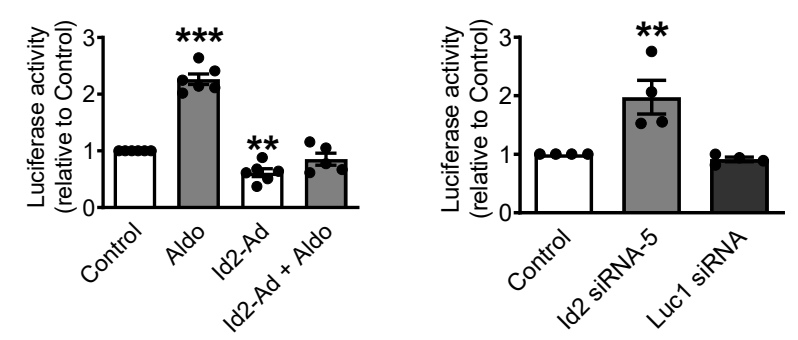

Figure 5. Id2 regulates the activity of CaV3.1 promoter. The luciferase reporter gene was placed under the control of $0.8 \mathrm{~kb}$ of the CaV3.1 promoter. The reporter gene was transected into neonatal rat cardiomyocytes to measure the luciferase activity upon Id2 overexpression (left) or Id2 siRNA knockdown (right). Bar graphs represent the mean of the relative activity of luciferase from the CaV3.1 luciferase reporter plasmid construct. The data were evaluated by one-way analysis of variance (ANOVA) followed by Tukey-Kramer's post hoc test. Values are mean + s.e.m., ${ }^{* * *} p<0.001$, ** $p<0.01(n=4-6)$.

A

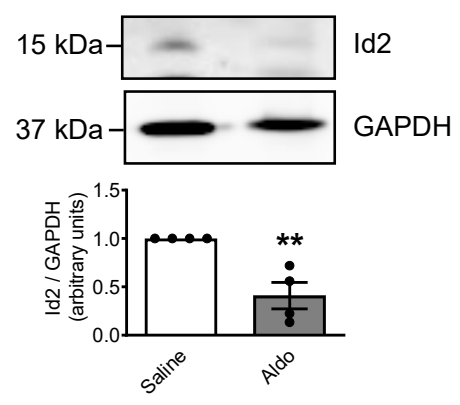

C

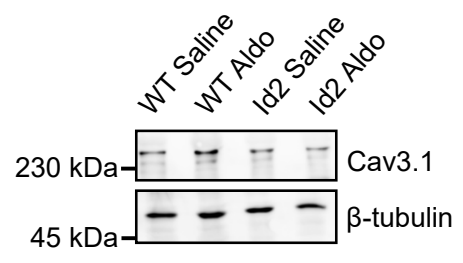

B
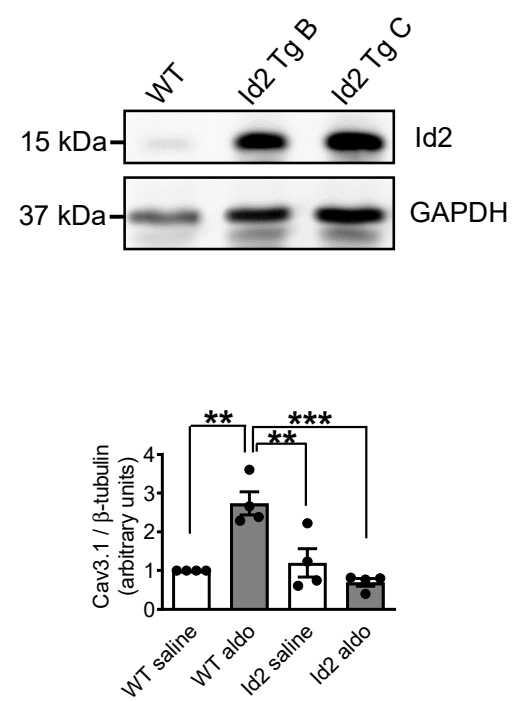

Figure 6. Id 2 expressing transgenic mice prevents the aldosterone-stimulated expression of CaV3.1 voltage-gated calcium channels in vivo. WT or cardiomyocyte-specific Id 2 expressing transgenic B6D2F1/Slc mice were stimulated with Aldosterone $(60 \mathrm{mg} / \mathrm{Kg} /$ day) or Saline solution for 1 week by implanting subcutaneously osmotic pumps. (A) Representative pictures of western blot experiments showing the Id2 protein (upper) and GAPDH protein (lower) expression levels from the heart of WT mice treated with saline solution or aldosterone. The bar graph is the mean of Id2 expression $(n=4)$. (B) Pictures of western blotting experiments showing the Id2 protein (upper) and GAPDH protein (lower) expression levels in the heart of B6D2F1/Slc WT and two cardiomyocyte-specific Id2 expressing transgenic (Tg) mice. (C) Pictures of western blotting experiments showing CaV3.1 (upper) and tubulin (lower) proteins expression levels in WT or Id2 transgenic mice treated with saline solution or aldosterone. Graph is are the mean expression of CaV3.1 and tubulin expression $(n=4)$. The data were evaluated by one-way analysis of variance (ANOVA) followed by TukeyKramer's post hoc test or by unpaired two-tailed Student's $t$-test. Bars and error bars indicate the mean \pm s.e.m., ${ }^{* *} p<0.01,{ }^{* * *} p<0.001$. 
Table 1. Physiological characteristics in transgenic mice at baseline.

\begin{tabular}{cccc}
\hline & WT $(\boldsymbol{n}=\mathbf{5})$ & Id2 Tg B $(\boldsymbol{n}=\mathbf{5})$ & Id2 Tg C $(\boldsymbol{n}=\mathbf{5})$ \\
\hline Body weight $(\mathrm{g})$ & $21.8 \pm 1.8$ & $21.1 \pm 1.3$ & $21.0 \pm 0.5$ \\
Whole heart weight $(\mathrm{mg})$ & $120.9 \pm 8.4$ & $119.2 \pm 8.5$ & $117.4 \pm 7.6$ \\
Lung weight $(\mathrm{mg})$ & $109.1 \pm 4.3$ & $108.8 \pm 2.9$ & $111.6 \pm 2.8$ \\
Liver weight $(\mathrm{mg})$ & $1004.2 \pm 13.6$ & $973.3 \pm 69.8$ & $1014.2 \pm 37.3$ \\
WHW/BW & $5.54 \pm 0.39$ & $5.64 \pm 0.15$ & $5.58 \pm 0.29$ \\
\hline
\end{tabular}

Table 2. Physiological characteristics of mice 1 week after saline and aldosterone infusion.

\begin{tabular}{ccccc}
\hline & $\begin{array}{c}\text { WT Saline } \\
(\boldsymbol{n}=\mathbf{8})\end{array}$ & $\begin{array}{c}\text { Id2 Saline } \\
(\boldsymbol{n}=\mathbf{6})\end{array}$ & $\begin{array}{c}\text { WT Aldo } \\
(\boldsymbol{n}=\mathbf{8})\end{array}$ & $\begin{array}{c}\text { Id2 Aldo } \\
(\boldsymbol{n}=\mathbf{5})\end{array}$ \\
\hline Body weight (g) & $24.3 \pm 1.2$ & $23.8 \pm 0.8$ & $25.1 \pm 0.4$ & $24.3 \pm 1.1$ \\
Whole heart weight (mg) & $127.5 \pm 13.2$ & $119.1 \pm 9.6$ & $155.8 \pm 15.8$ & $133.9 \pm 5.8$ \\
Lung weight (mg) & $121.3 \pm 10.3$ & $111.9 \pm 3.6$ & $137.9 \pm 9.6$ & $126.7 \pm 4.0$ \\
Liver weight (mg) & $1129.9 \pm 77.4$ & $1076.3 \pm 63.3$ & $1105.6 \pm 37.9$ & $1112.1 \pm 45.3$ \\
WHW/BW & $5.22 \pm 0.43$ & $4.97 \pm 0.28$ & $6.20 \pm 0.61$ & $5.51 \pm 0.11$ \\
\hline
\end{tabular}

Table 3. Characteristics of mice 1 week after saline and aldosterone infusion.

\begin{tabular}{cccc}
\hline & Saline $(\boldsymbol{n}=\mathbf{5})$ & Aldo $(\boldsymbol{n}=\mathbf{8})$ & $p$ Value \\
\hline Body weight $(\mathrm{g})$ & $23.8 \pm 1.2$ & $25.2 \pm 0.8$ & 0.318 \\
Whole heart weight $(\mathrm{mg})$ & $118.4 \pm 14.2$ & $149.8 \pm 17.9$ & 0.244 \\
Lung weight $(\mathrm{mg})$ & $116.1 \pm 9.2$ & $140.0 \pm 10.2$ & 0.138 \\
Liver weight $(\mathrm{mg})$ & $1081.6 \pm 93.7$ & $1141.6 \pm 71.8$ & 0.618 \\
WHW/BW & $4.95 \pm 0.46$ & $5.96 \pm 0.70$ & 0.319 \\
\hline
\end{tabular}

\section{Material and Methods}

\subsection{Animals}

All experiments on animals were conducted according to the institutional animal care and use committee-approved protocol at Nagoya University (Aichi, Japan) and Nagaoka University of Technology (Niigata, Japan).

\subsection{Id2 Transgenic Mice}

Rat Id 2 cDNA was isolated by RT-PCR with the forward primer obtained HindIII enzyme site $5^{\prime}$-GACAAGCTTATGAAAGCCTTCAGT-3' and the reverse primer obtained EcoRV enzyme site $5^{\prime}$-ATAGATATCTTAGCCACAGAGTAC-3' from rat heart total RNA. Rat Id 2 cDNA was cloned into the plasmid vector containing $\alpha$-myosin heavy chain $(\alpha-\mathrm{MHC})$ promoter which is heart specific isoform of MHC. This plasmid vector was kindly provided by Professor K. Otsu (King's College London, London, UK). The $\alpha$-MHC promoter-rat Id2-SV40 region was linearized and gel purified. The NPO for Biotechnology Research and Development performed microinjection into the pronuclear of DBF1 mouse zygotes. Transgenic (TG) mice were identified by PCR with the forward primer $5^{\prime}$-GCCCACACCAGAAATGAC- $3^{\prime}$ that is specific sequence for $\alpha$-MHC promoter and the reverse primer $5^{\prime}$-ATGCTGATGTCCGTGTTCAG-3 ${ }^{\prime}$ that is specific sequence for Id2. Id2 TG mice were crossed with B6D2F1/Slc mice (SLC Japan, Shizuoka, Japan), and the male hetero F2 mice were used. The littermates of TG mice that did not contain transgene were used as control mice. All mice were analyzed at 8- to 12-weeks-old.

\subsection{Aldosterone Treatment}

The three types of mixed anesthetic agents $(0.3 \mathrm{mg} / \mathrm{kg}$ of medetomidine, $4.0 \mathrm{mg} / \mathrm{kg}$ of midazolam, and $5.0 \mathrm{mg} / \mathrm{kg}$ of butorphanol) were used as anesthesia for experimental mice. The 8- to 12-week-old mice were implanted micro-osmotic pumps (Alzet, DURECT 
Co., Cupertino, CA, USA, model; 1007D) filled with $60 \mathrm{mg} / \mathrm{Kg}$ /day aldosterone (SigmaAldrich, St. Louis, MO, USA) or with saline subcutaneously. A week after the operation, animals were sacrificed by cervical dislocation. The hearts, lungs, and livers were weighed. Subsequently, the left tibia was dissected and the length of the bone was measured.

\subsection{Cardiomyocyte Isolation and Culture}

Isolation of neonatal rat ventricular myocytes were previously described [16]. The cardiomyocytes were transferred to culture plates, and fibroblasts were removed by adhesion onto the plates for $1 \mathrm{~h}$. The cardiomyocytes were then plated overnight and maintained in DMEM (Nacalai Tesque, Kyoto, Japan) containing 10\% fetal bovine serum (Gibco, Auckland, New Zealand), $2 \mathrm{mmol} / \mathrm{L}$ L-glutamine, $100 \mathrm{U} / \mathrm{mL}$ penicillin and $100 \mathrm{mg} / \mathrm{mL}$ streptomycin (Nacalai Tesque, Kyoto, Japan).

\subsection{RT-PCR Analysis}

Rat brain, atria, septum, right and left ventricle, end cardial, middle layer, and epi cardial were extracted from adult rat. The first-strand cDNA was synthesized using a commercial kit (ReverTra Ace qPCR RT Kit, Toyobo, Tokyo, Japan) according to the manufacturer's instructions. Standard PCR was performed in a final volume of $25 \mu \mathrm{L}$ containing synthesized cDNA ( $25 \mathrm{ng}$ of RNA content), $400 \mathrm{nmol} / \mathrm{L}$ primers and commercial master mix (EmeraldAmp MAX PCR Master Mix, Takara, Otsu, Shiga, Japan). PCR conditions were $98^{\circ} \mathrm{C}$ for $5 \mathrm{~s}, 60^{\circ} \mathrm{C}$ for $5 \mathrm{~s}$, and $72{ }^{\circ} \mathrm{C}$ for $60 \mathrm{~s}$ for $25-27$ cycles with the final extension at $72{ }^{\circ} \mathrm{C}$ for $4 \mathrm{~min}$. The PCR products were resolved by electrophoresis on a $2 \%$ agarose gel and stained with $0.5 \mu \mathrm{g} / \mathrm{mL}$ ethidium bromide. The whole pictures of RT-PCR experiments results shown in Figure S1 are shown in Figure S6.

\subsection{Real-Time Quantitative PCR Analysis}

Real-time PCR was done with synthesized cDNA (50 ng of RNA content), $200 \mathrm{nM}$ primers and commercial master mix (Power SYBR Green PCR Master Mix, Applied Biosystems, Warrington, UK) in a final volume of $25 \mu \mathrm{L}$ and normalized to GAPDH. The PCR reaction was carried out in 96-well plates using Stratagene Mx3000P (Agilent Technologies). The primers used in the experiments are shown in Table 4.

Table 4. Primer sequences used for RT or real-time PCR.

\begin{tabular}{|c|c|c|}
\hline & Forward $5^{\prime}-3^{\prime}$ & Reverse $5^{\prime}-3^{\prime}$ \\
\hline Rat Id2 & CTCCAAGCTCAAGGAACTGG & ATGCTGATGTCCGTGTTCAG \\
\hline Rat CaV1.2 & AGCAACTTCCCTCAGACGTTTG & GCTTCTCATGGGACGGTGAT \\
\hline Rat CaV3.1 & ACGCTGAGTCTCTCTGGTTTGTC & TGCTTACGTGGGACTTTTCAGA \\
\hline Rat CaV3.2 & GGCGAAGAAGGCAAAGATGA & GCGTGACACTGGGCATGTT \\
\hline Rat GAPDH & САAСТСССТСAAGATTGTCAGCAA & GGCATGGACTGTGGTCATGA \\
\hline Rat Hcn2 & GGACACTTTCTTCCTCATGGAC & CTCCGTGTTGTCCTCAATAAC \\
\hline Rat Hcn 4 & СТTССТСATTGACTTGGTCСTC & TACTTCATCTTGATCCGCTGTG \\
\hline Rat Kcnh2 & ACCTTCAACCTTCGAGATACCAAC & GCTCTGTGTCCTTGTCAGTACG \\
\hline Rat Kcnd3 & GACAAGAACAAGCGGCAAGA & GCATTCATAGCGTGGGTAGT \\
\hline Rat Scn5a & ACCTGCCTCTGAACTACACCATC & CCTTGGTCCAGTACAACTCTCC \\
\hline
\end{tabular}

\subsection{Luciferase Reporter Assay}

The rat cacna1g promoter region $(-798 /+694 \mathrm{bp})$ was generated by PCR with primers (5'-CTGTTTCACTCAGCAATGATC-3' and 5'-GGTAGAAGTTGAGCACACAACGG-3') using genomic DNA from neonatal rat ventricular myocytes. The cacnalg promoter region PCR fragment was subcloned into pUC118 vector using a commercial kit (Mighty Cloning Reagent Set (Blunt End), TaKaRa, Shiga, Japan). After confirming the direction of the fragment, approximately $1.5 \mathrm{~kb}$ of a KpnI/HindIII digested fragment was subcloned into the pGL3-basic vector (Promega, Madison, WI, USA). 
On the second day after neonatal rat ventricular myocytes isolation, cells were infected by Id2-adenovirus. After $24 \mathrm{~h}$, cells were transfected with $800 \mathrm{ng}$ of the cacna1g promoter luciferase and $200 \mathrm{ng}$ control vector pRL-null using Lipofectamine 3000 in Opti-MEM (Invitrogen, Carlsbad, CA, USA). Then, $24 \mathrm{~h}$ after transfection, cells were stimulated by $1 \mu \mathrm{mol} / \mathrm{L}$ aldosterone. After $24 \mathrm{~h}$ stimulation, luciferase activities were measured using dual-luciferase reporter assay system (Promega, Madison, WI, USA).

\subsection{RNA Interference}

Small interfering RNAs (siRNAs) targeting rat Id2 were designed with forward sequences (upper strand) as follows: Id2-2, AAACAGCCUGUCGGACCACATT and Id25, CCCGAUGAGUCUGCUCUACATT. These sequences were blasted against the NCBI database and showed no recognition of other rat ORFs. siRNAs were produced by (Operon, Tokyo, Japan) and transfected using a transfection reagent, Lipofectamine RNAiMAX Transfection Reagent, following the manufacturer's instructions (Invitrogen).

\subsection{Plasmid Construction}

Rat Id 2 cDNA was obtained by RT-PCR with the primers 5'-GCCTTTCCTCCTACG AGCAGCAT- $3^{\prime}$ and 5'-AGCCACAGAGTACTTTGCT GTCATTC- $3^{\prime}$ using total RNA isolated from the ventricular heart of adult male Sprague-Dawley rats. The obtained PCR product was cloned into pCR-BluntII-TOPO vector (Invitrogen, Carlsbad, CA, USA). Rat Id 2 cDNA was inserted into the HindIII/SalI sites of the shuttle vector pDC316 for adenovirus production.

\subsection{Adenovirus}

Recombinant human adenoviruses- 5 for gene delivery of Id 2 was produced in HEK293 cells, amplified and purified by $\mathrm{CsCl}$ gradients as previously described [28].

\subsection{Western Blot}

Proteins from neonatal rat ventricle cardiomyocytes were extracted using a lysis buffer (in mmol/L: 50 Tris at pH 7.6, 400 NaCl, 5 EDTA, 1 DTT, 1 PMSF, 1\% NP-40, 10\% glycerol and a tablet of protease inhibitors; Roche). Proteins from freshly isolated mouse ventricle of control and Id2 transgenic mice were lysed in $200 \mu \mathrm{L}$ lysis buffer. The obtained homogenates were centrifuged at 10,000 rpm for $5 \mathrm{~min}$ to remove any remaining large cellular fragments. Total cell lysates $(60 \mu \mathrm{g}$ proteins for calcium channels and $100 \mu \mathrm{g}$ proteins for Id2) were resolved by $8 \%$ SDS-polyacrylamide gel electrophoresis (SDS-PAGE) for calcium channels and 15\% gel for GAPDH and Id2. Proteins were transferred to polyvinylidene difluoride membranes (Millipore, Billerica, MA, USA) and immunoblotted with an anti-Id2 monoclonal antibody (Cell Signaling Technology, Danvers, MA, USA), an anti-CaV3.1 polyclonal antibody (Alomone Labs, Jerusalem, Israel), an anti-CaV1.2 polyclonal antibody (Alomone Labs, Jerusalem, Israel), anti-Cav3.2 polyclonal antibody (Alomone Labs, Jerusalem, Israel), an anti-GAPDH polyclonal antibody (Novus Biologicals, Littleton, Colorado, USA), and an anti- $\beta$-tubulin monoclonal antibody (Sigma-Aldrich, St. Louis, MO, USA). As secondary antibodies for detection, anti-mouse or an anti-rabbit IgG linked to horseradish peroxidase (Jackson Immuno Research, West Grove, PA, USA) were used, respectively. The whole pictures of western blots experiments results shown in Figure 1, Figure 2, Figure 6, Figures S1 and S4 are shown in Figures S5 and S6.

\subsection{Electrophysiology}

Voltage-gated $\mathrm{Ca}^{2+}$ currents and spontaneous action potentials were recorded by the patch-clamp technique, as previously described [10]. Briefly cardiomyocytes were cultured on poly-lysine coated glass dishes. Recordings were performed in the wholecell configuration using an Axopatch 200B Amplifier (Axon CNS, Molecular Devices, Sunnyvale, CA, USA) at a holding potential of $-90 \mathrm{mV}$. Cells were depolarized from the $-90 \mathrm{mV}$ holding potential to $-80 \mathrm{mV}$ with $+10 \mathrm{mV}$ voltage steps of $200 \mathrm{~ms}$. The 
current amplitude was measured at the peak. To establish the current density-voltage curve, the current density was determined with the cell capacitance. The mean $\pm \mathrm{SD}$ cell capacitances were: control cells: $13.8 \pm 2.73$ pF; aldosterone treated cells: $20.3 \pm 4.5$ pF; Id2Ad: $14.7 \pm 5.1 \mathrm{pF}$; Id2-Ad + aldosterone treated: $17.1 \pm 4.2 \mathrm{pF}$; Id2-siRNA: $16.9 \pm 4.46 \mathrm{pF}$; siRNA-luc: $15.4 \pm 4.04$ ( $n=7-12$ cells, as shown in Figure 4$)$. The currents were filtered at $2 \mathrm{kHz}$ and sampled at $5 \mathrm{kHz}$ using a A/D converter, the Digidata 1440A (Axon CNS, Molecular Devices, Sunnyvale, CA). The leak was subtracted automatically by a P/4 protocol (pclamp10, Axon CNS, Molecular Devices, Sunnyvale, CA). For the recording $\mathrm{Ca}^{2+}$ currents, the bath solution contained (in mmol/L) $125 \mathrm{~N}$-methyl-glucamine, 54aminopyridine, 20 tetraethyl-ammonium chloride, $2 \mathrm{CaCl}_{2}, 2 \mathrm{MgCl}_{2}$, and $10 \mathrm{D}$-glucose and was buffered to $\mathrm{pH} 7.4$ with $10 \mathrm{HEPES}$. The patch pipettes were filled with solution containing (in mmol/L) $130 \mathrm{CsCl}, 10$ EGTA, $3 \mathrm{Mg}$-ATP and $0.4 \mathrm{Li}-\mathrm{GTP}$ with the $\mathrm{pH}$ adjusted to 7.2 by 25 HEPES. Spontaneous action potentials were recorded in the $\mathrm{I}=0$ mode of the Axopatch 200B Amplifier with a bath solution (in mmol/L): $146.9 \mathrm{NaCl}, 5.4 \mathrm{KCl}$, $1.8 \mathrm{CaCl}_{2}, 0.33 \mathrm{NaH}_{2} \mathrm{PO}_{4}$ and 5 Hepes, with the $\mathrm{pH}$ adjusted to 7.4 by $\mathrm{NaOH}$ and a pipette solution (in mmol/L): $60 \mathrm{KOH}, 60 \mathrm{KCL}, 40$ Aspartate, 10 EGTA, 5 Hepes, $5 \mathrm{Mg}$-ATP, $5 \mathrm{Na}-\mathrm{Phosphocreatine}$ and $0.65 \mathrm{CaCl}_{2}$ with the $\mathrm{pH}$ adjusted to 7.2 by $\mathrm{KOH}$.

\subsection{Statistical Analysis}

Results are shown as the mean \pm S.E.M. Statistical analysis was performed by a Student's $t$-test for paired data or one-way ANOVA, followed by Tukey-Kramer's post hoc test was used for multiple comparisons. ${ }^{*} p<0.05,{ }^{* *} p<0.01$, and ${ }^{* * *} p<0.001$.

\section{Discussion}

In the present study, we found that the transcriptional repressor Id2 expression is repressed by aldosterone in neonatal rat cardiomyocytes and the adult mouse heart. The overexpression of Id 2 in cardiomyocytes prevented the aldosterone-stimulated an increase in spontaneous action potential rate while the knock down of Id2's expression increased this rate similar with the aldosterone effect. Similarly, these effects were also observed for the expression of voltage-gated $\mathrm{Ca}^{2+}$ channels and $\mathrm{Ca}^{2+}$ currents. Taken altogether these results suggest that Id 2 can function as a repressor of voltage-gated $\mathrm{Ca}^{2+}$ channels expression particularly CaV3.1 T-type $\mathrm{Ca}^{2+}$ channels.

The increase in voltage-gated $\mathrm{Ca}^{2+}$ channels expression $(\mathrm{CaV} 1.2, \mathrm{CaV} 3.1$, and $\mathrm{CaV} 3.2)$ and their $\mathrm{Ca}^{2+}$ currents in cardiomyocytes stimulated with aldosterone was previously reported $[11,12,26]$ and is consistent with our present results. Interestingly, when Id2 was overexpressed in neonatal rat ventricular cardiomyocytes, the aldosterone-stimulated increase in voltage-gated $\mathrm{Ca}^{2+}$ channels expression was suppressed, as well as the rate of their spontaneous action potentials, confirming their role in pacing the cardiomyocytes electrical activity. We confirmed in vivo the repressive effect of Id 2 on voltage-gated $\mathrm{Ca}^{2+}$ channels expression in the heart of mice. These results thus confirmed that Id 2 can block the aldosterone-stimulated transcription in cardiomyocytes. The interaction of Id 2 with transcription factors prevents their binding to the promotor of their target genes preventing their expression [17]. The transcription factors whose activity is repressed by Id2 before its downregulation by aldosterone stimulation remain to be identify.

Aldosterone has been shown to up regulate or down regulate different type of genes, including transcription factors or transcriptional regulator [27]. Our results suggest that Id 2 is another transcriptional regulator whose expression is regulated by aldosterone in the heart. The aldosterone stimulated repression is dependent on MR activation but does not appear to involve in the $3.1 \mathrm{~kb}$ promoter region of Id 2 despite the presence of 21 predicted MR cis-binding consensus sequence. Therefore, the repression of Id 2 might involve other regulatory mechanisms such as specific micro RNAs. The expression of the transcriptional repressor NRSF/REST is also down regulated by aldosterone and miRNA204, a miRNA upregulated by aldosterone, overexpression [16]. A similar mechanism involving a yet unidentified miRNA might downregulate Id2 upon aldosterone. 
Interestingly, the siRNA knockdown of Id2 resulted only in an increase expression of CaV3.1 but not of CaV1.2 and CaV3.2 (Figure 3B). The absence of effect by the Id2 siRNA on CaV3.2 isoforms might be due to another transcriptional repressor, REST/NRSF, which represses also CaV3.2 expression but not CaV3.1 expression [29]. Thus, the repression of both Id2 and REST/NRSF should be necessary to enable the transcriptional activation of CaV3.2. Transcriptional repressors have been shown to provide cardiomyocytes a protective mechanism to counter the activation of pathological transcription [30]. The re-expression of T-type $\mathrm{Ca}^{2+}$ channels in the heart ventricle plays a role in the development of cardiac hypertrophy and heart failure [16]. The transcriptional repression of T-type $\mathrm{Ca}^{2+}$ could be therefore an efficient mechanism to protect the heart. Aldosterone excess would overcome the Id 2 repression to stimulate the T-type $\mathrm{Ca}^{2+}$ increased re-expression. Further experience would be required to confirm this hypothesis and identify other potential targets of Id2 transcriptional repression.

In conclusion, taken all together our results suggest a pathway in which MR activation aldosterone stimulated the repression of Id 2 expression, which in-turn might enable the re-expression of CaV3.1 T-type $\mathrm{Ca}^{2+}$ channels in ventricular cardiomyocytes triggering increased rate of spontaneous action potentials. In addition, the capacity of Id 2 to prevent the aldosterone-stimulated increased expression of $\mathrm{L}$ - and T-type voltage-gated $\mathrm{Ca}^{2+}$ channels suggests a protective capacity for Id 2 in cardiomyocytes. Further analysis in vivo would be necessary to confirm this hypothesis.

Supplementary Materials: The following are available online at https://www.mdpi.com/article/10 $.3390 /$ ijms22073561/s1.

Author Contributions: All authors contributed to the research of the present study. J.I., T.M., S.W., T.N., Y.F., S.K., K.T., and A.D.M. performed the experiments, analyzed and interpreted the data. J.I., S.W., and A.D.M. drafted the manuscript. J.I. and A.D.M. conceptualized the study. All authors have read and agreed to the published version of the manuscript.

Funding: This work was supported by a grant of the Japan Society for the Promotion of Science, Kiban C, to A.D.M. (Project number: 24570150) and Grant-in-Aid for JSPS Fellows to J.I. (Project number: 26002967).

Institutional Review Board Statement: The study was conducted according to the guidelines of the Declaration of Helsinki, and approved by the Ethics Committee of Nagoya University (201504902 and 9 April 2015.

Informed Consent Statement: Not applicable.

Data Availability Statement: Please refer to suggested Data Availability Statements in section “MDPI Research Data Policies" at https: / www.mdpi.com/ethics (accessed on 30 March 2021).

Acknowledgments: We thank NPO Biotechnology Research and Development for technical assistance in the generation of the Id 2 transgenic mice.

Conflicts of Interest: The authors declare no conflict of interest.

\section{References}

1. Essick, E.E.; Sam, F. Cardiac hypertrophy and fibrosis in the metabolic syndrome: A role for aldosterone and the mineralocorticoid receptor. Int. J. Hypertens. 2011, 2011, 346985. [CrossRef]

2. Lother, A.; Moser, M.; Bode, C.; Feldman, R.D.; Hein, L. Mineralocorticoids in the heart and vasculature: New insights for old hormones. Annu. Rev. Pharmacol. Toxicol. 2015, 55, 289-312. [CrossRef] [PubMed]

3. Funder, J.W. Aldosterone, hypertension and heart failure: Insights from clinical trials. Hypertens. Res. 2010, 33, 872-875. [CrossRef]

4. Gravez, B.; Tarjus, A.; Jaisser, F. Mineralocorticoid receptor and cardiac arrhythmia. Clin. Exp. Pharmacol. Physiol. 2013, 40, 910-915. [CrossRef]

5. Patramela, L.; Concistrè, A.; Olmati, F.; Saracino, V.; Chimenti, C.; Frustaci, A.; Russo, M.A.; Letizia, C. Cardiomyopathies and Adrenal Diseases. Int. J. Mol. Sci. 2020, 21, 5047. [CrossRef]

6. Funder, J.W. Aldosterone and mineralocorticoid receptors: A personal reflection. Mol. Cell. Endocrinol. 2021, 350, 146-150. [CrossRef] 
7. Benitah, J.P.; Vassort, G. Aldosterone upregulates Ca(2+) current in adult rat cardiomyocytes. Circ. Res. 1999, 85, 1139-1145. [CrossRef]

8. Ouvrard-Pascaud, A.; Sainte-Marie, Y.; Benitah, J.P.; Perrier, R.; Soukaseum, C.; Nguyen Dinh Cat, A.; Royer, A.; Le Quang, K.; Charpentier, F.; Demolombe, S. Conditional mineralocorticoid receptor expression in the heart leads to life-threatening arrhythmias. Circulation 2005, 111, 3025-3033. [CrossRef]

9. Martin-Fernandez, B.; Miana, M.; De Las Heras, N.; Ruiz-Hurtado, G.; Fernandez-Velasco, M.; Bas, M.; Ballesteros, S.; Lahera, V.; Cachofeiro, V.; Delgado, C. Cardiac L-type calcium current is increased in a model of hyperaldosteronism in the rat. Exp. Physiol. 2009, 94, 675-683. [CrossRef]

10. Maturana, A.; Lenglet, S.; Python, M.; Kuroda, S.; Rossier, M.F. Role of the T-Type Calcium Channel Ca(V)3.2 in the Chronotropic Action of Corticosteroids in Isolated Rat Ventricular Myocytes. Endocrinology 2009, 150, 3726-3734. [CrossRef]

11. Lalevee, N.; Rebsamen, M.C.; Barrere-Lemaire, S.; Perrier, E.; Nargeot, J.; Benitah, J.P.; Rossier, M.F. Aldosterone increases T-type calcium channel expression and in vitro beating frequency in neonatal rat cardiomyocytes. Cardiovasc. Res. 2005, 67, 216-224. [CrossRef] [PubMed]

12. Ferron, L.; Ruchon, Y.; Renaud, J.F.; Capuano, V. T-type Ca2+ signalling regulates aldosterone-induced CREB activation and cell death through PP2A activation in neonatal cardiomyocytes. Cardiovasc. Res. 2011, 90, 105-112. [CrossRef] [PubMed]

13. Ono, K.; Iijima, T. Cardiac T-type Ca(2+) channels in the heart. J. Mol. Cell. Cardiol. 2010, 48, 65-70. [CrossRef]

14. Chiang, C.S.; Huang, C.H.; Chieng, H.L.; Chang, Y.T.; Chang, D.R.; Chen, J.J.; Chen, Y.C.; Chen, Y.H.; Shin, H.S.; Campbell, K.P.; et al. The Ca(v)3.2 T-Type Ca2+ Channel Is Required for Pressure Overload-Induced Cardiac Hypertrophy in Mice. Circ. Res. 2009, 104, 522-530. [CrossRef]

15. BenMohamed, F.; Ferron, L.; Ruchon, Y.; Gouadon, E.; Renaud, J.F.; Capuano, V. Regulation of T-type Cav3.1 channels expression by synthetic glucocorticoid dexamethasone in neonatal cardiac myocytes. Mol. Cell. Biochem. 2010, 335, 47-51. [CrossRef] [PubMed]

16. Koyama, R.; Mannic, T.; Ito, J.; Amar, L.; Zennaro, M.-C.; Rossier, M.F.; Maturana, A.D. MicroRNA204 is necessary for aldosteronestimulated T-type calcium channel expression in cardiomyocytes. Int. J. Mol. Sci. 2018, 19, 2941. [CrossRef]

17. Wong, M.V.; Jiang, S.; Palasingam, P.; Kolatkar, P.R. A divalent ion is crucial in the structure and dominant-negative function of ID proteins, a class of helix-loop-helix transcription regulators. PLoS ONE 2012, 7, e48591. [CrossRef]

18. Fraidenraich, D.; Stillwell, E.; Romero, E.; Wilkes, D.; Manova, K.; Basson, C.T.; Benezra, R. Rescue of cardiac defects in id knockout embryos by injection of embryonic stem cells. Science 2004, 306, 247-252. [CrossRef]

19. Moskowitz, I.P.; Wang, J.; Peterson, M.A.; Pu, W.T.; Mackinnon, A.C.; Oxburgh, L.; Chu, G.C.; Sarkar, M.; Berul, C.; Smoot, L.; et al. Transcription factor genes Smad4 and Gata4 cooperatively regulate cardiac valve development. Proc. Natl. Acad. Sci. USA 2011, 108, 4006-4011. [CrossRef]

20. Moskowitz, I.P.; Kim, J.B.; Moore, M.L.; Wolf, C.M.; Peterson, M.A.; Shendure, J.; Nobrega, M.A.; Yokota, Y.; Berul, C.; Izumo, S.; et al. A molecular pathway including Id2, Tbx5, and Nkx2-5 required for cardiac conduction system development. Cell 2007, 129, 1365-1376. [CrossRef]

21. Ding, B.; Liu, C.J.; Huang, Y.; Yu, J.; Kong, W.; Lengyel, P. p204 protein overcomes the inhibition of the differentiation of P19 murine embryonal carcinoma cells to beating cardiac myocytes by Id proteins. J. Biol. Chem. 2006, 281, 14893-14906. [CrossRef]

22. Lim, J.Y.; Kim, W.H.; Kim, J.; Park, S.I. Induction of Id2 expression by cardiac transcription factors GATA4 and Nkx2. J. Cell. Biochem. 2008, 103, 182-914. [CrossRef]

23. Messaoudi, S.; Gravez, B.; Tarjus, A.; Pelloux, V.; Ouvrard-Pascaud, A.; Delcayre, C.; Samuel, J.; Launay, J.M.; Sierra-Ramos, C.; de la Rosa, D.A.; et al. Aldosteron-specific activation of cardiomyocyte mineralocorticoid receptor in-vivo. Hypertension 2013, 61, 361-367. [CrossRef] [PubMed]

24. Jongbloed, M.R.; Vicente-Steijn, R.; Douglas, Y.L.; Wisse, L.J.; Mori, K.; Yokota, Y.; Bartelings, M.M.; Schalij, M.J.; Mahtab, E.A.; Poelmann, R.E.; et al. Expression of Id2 in the second heart field and cardiac defects in Id2 knock-out mice. Dev. Dyn. 2011, 240, 2561-2577. [CrossRef] [PubMed]

25. Rossier, M.F.; Python, M.; Maturana, A.D. Contribution of Mineralocorticoid and Glucocorticoid Receptors to the Chronotropic and Hypertrophic Actions of Aldosterone in Neonatal Rat Ventricular Myocytes. Endocrinology 2010, 151, 2777-2787. [CrossRef]

26. Perrier, E.; Kerfant, B.G.; Lalevee, N.; Bideaux, P.; Rossier, M.F.; Richard, S.; Gómez, A.M.; Benitah, J.P. Mineralocorticoid receptor antagonism prevents the electrical remodeling that precedes cellular hypertrophy after myocardial infarction. Circulation 2004, 110, 776-783. [CrossRef]

27. Bienvenu, L.A.; Reichelt, M.E.; Delbridge, L.M.D.; Young, M.J. Mineralocorticoid receptors and the heart, multiple cell types and multiple mechanisms: A focus on the cardiomyocyte. Clin. Sci. 2013, 125, 409-421. [CrossRef]

28. Maturana, A.D.; Walchli, S.; Iwata, M.; Ryser, S.; Van Lint, J.; Hoshijima, M.; Schlegel, W.; Ikeda, Y.; Tanizawa, K.; Kuroda, S. Enigma homolog 1 scaffolds protein kinase D1 to regulate the activity of the cardiac L-type voltage-gated calcium channel. Cardiovasc. Res. 2008, 78, 458-465. [CrossRef]

29. Kuwahara, K.; Saito, Y.; Takano, M.; Arai, Y.; Yasuno, S.; Nakagawa, Y.; Takahashi, N.; Adachi, Y.; Takemura, G.; Horie, M.; et al. NRSF regulates the fetal cardiac gene program and maintains normal cardiac structure and function. EMBO J. 2003, 22, $6310-6321$. [CrossRef]

30. Guo, A.; Wang, Y.; Chen, B.; Wang, Y.; Yuan, J.; Zhang, L.; Hall, D.; Wu, J.; Shi, Y.; Zhu, Q.; et al. E-C coupling structural protein junctophilin-2 encodes a stress-adaptative transcription regulator. Science 2018, 362, eaan3303. [CrossRef] 